\title{
The relevance of annual general meetings: recent evidence from the UK
}

\section{Lawal Tolulola}

School of Finance and Management

SOAS University of London, UK

Email: t15@soas.ac.uk

\begin{abstract}
Using over 14,000 hand-collected annual general meeting dates of UK firms over the period 2004 to 2014, the study provides some evidence in support of the information content hypothesis from the analysis of price and volume reactions around annual general meetings. In addition, the study finds some support for an increase in the information content of annual general meetings during the study period. Our results show that both the magnitude of abnormal return and the temporal variation in the information content of annual general meetings depend on a number of firm characteristics that capture firms' information environment.
\end{abstract}

Keywords: corporate governance; annual general meetings; information content hypothesis; event study; abnormal return; abnormal volume; UK; United Kingdom. 


\section{INTRODUCTION}

The Companies Act (U.K. Parliament, 2006) and the UK Corporate Governance Code (Financial Reporting Council, 2014) recognise the importance of the annual general meeting (AGM). However, the UK's Department of Trade and Industry, through its Company Law Review Steering Group once considered the idea of dispensing with the need for public companies to hold AGMs. While respondents to the group's consultation document were critical of the effectiveness of AGMs, a majority of respondents objected to the proposal to dispense with AGMs (see Table 2, Strätling, 2003:78). This study revisits the debate on the role of AGMs in the UK by examining the stock market reaction to AGMs. Using our comprehensive hand-collected database of over 14,000 AGM dates from 2004 to 2014, the study examines the information content hypothesis of AGMs by analysing price and volume changes around AGMs. The study examines for the first time the evolution of the information content of AGMs in the context of firms' information environment, especially given the increase in sources of corporate communication over the last decade. ${ }^{1}$

Strätling (2003) presents three main functions of the AGM: to inform shareholders about the company's financial results and significant management decisions; to obtain shareholders' approval of the decisions that are outside the powers of the board of directors; and to provide a forum for discussion between managers and shareholders on the past performance and future actions and prospects of the company. The empirical evidence on these issues suggests that AGMs are ineffective as a corporate governance tool for protecting the rights of minority shareholders and, therefore, dispensable (Strätling, 2003). However, Olibe (2002) argues that the mandatory nature of AGMs, the participation by investors and the provision of forwardlooking and qualitative information by management at the AGMs all suggest the indispensable nature of AGMs in providing incremental value-relevant information. Empirical evidence suggests that AGMs provide management with the opportunity to disseminate valuable 
information to shareholders especially during the period pre-dating the annual general meeting in order to address the concerns of shareholders and activist investors regarding such issues as the performance of the company, executive compensation and the company's proposed direction for the future. In line with this value relevant role of the AGMs, Dimitrov and Jain (2011) document a statistically significant positive abnormal returns ranging between $3 \%$ and $7 \%$ on average during the 40 days pre-dating an annual general meeting. The authors report that the value relevance of AGMs is even more pronounced for firms with relatively poor performance.

However, the idea that the market relies on the information associated with AGMs has received limited attention of financial economists especially outside the US (see, however, García-Blandón et al., 2012; Martinez-Blasco et al., 2015). In view of the value-relevance property of AGMs, Martinez-Blasco et al. (2015) argue that the AGMs deserve a more in-depth analysis. We address this issue using our large and purposely constructed database of UK AGM dates spanning a period of 11 years. We compute and test for the significance of abnormal return and abnormal volume, our proxies for the information content of AGMs. In addition, while controlling for firm-specific determinants of the information content of AGMs, we further conduct a longitudinal analysis which examines the time-varying pattern of the information content of AGMs.

We provide evidence that the market reacts significantly positively on the AGM dates. The result holds for both abnormal return and abnormal volume. Our results are generally consistent whatever the return generating process adopted in the study: market model and market return model. However, over longer event windows, our results are generally consistent with significantly negative price market reactions to AGMs even though abnormal number of trade, volume of shares and value of traded shares remain significantly positive over these windows. Overall, the evidence supports the idea that AGMs are value relevant but gives inconsistent 
indications regarding the direction of returns for different specifications of event windows. We find that on average the market reaction to AGMs ranges between $0.09 \%$ and $-1.65 \%$ depending on the length of event window considered. A further analysis of abnormal return provides evidence of significantly positive increase in the information content of AGMs over the last decade. The change in the information content of AGMs is linked to variation in firm characteristics including firm size and stock liquidity. However, we find no support for a change in trend in the information content of AGMs from our analysis of change in abnormal volume around AGMs during the study period. Finally, we note that ours is a study of AGMs at the aggregate level and does not examine the differential information impact of the various issues typically considered at an AGM; we do not address how and which of these issues explain the information content of AGMs. Therefore, our primary research question is whether these issues jointly result, on average, in the transfer of positive or negative value relevant information to the market thus underlying the importance of the AGM as a communication and corporate governance tool.

The remainder of this study is organised as follows. Section 2 presents a review of the relevant literature; Section 3 discusses the sample and methodology adopted in this study; Section 4 presents and discusses the empirical findings; Section 5 concludes the paper and provides a summary of findings.

\section{LITERATURE REVIEW}

The relationship between the release of public information and stock market variables such as stock returns and volume of trades has always gained the attention of financial economists since the seminal study of Beaver (1968) who examines the information content of earnings announcements. These studies argue that the release of new and relevant information results in significant changes in price reflecting changes in overall market expectations (Beaver, 1968) 
and changes in trading volume reflecting changes in traders' idiosyncratic preference for the shares of the firm (Kim and Verrecchia, 1991). In particular, Kyle (1985) argues that high trading volume around a corporate event is associated with the release of new information. Related information content studies examine the informational role of corporate events such as dividend announcements (e.g. Denis et al., 1994), stock split (e.g. Chen et al., 2011), directors changes (Warner et al., 1988). However, while companies' AGMs are an important source of dispensing information to shareholders, the limited amount of studies examining the information content of AGMs draws conclusions from a very limited amount of data covering a short period.

Firth (1981) provides the first evidence on the information content of AGMs. Using a sample of weekly stock data for 120 firms listed on the UK stock market over the period 19761978, the author examines the informational role of preliminary announcements (PAs), annual reports and accounts (ARAs) and AGMs by examining price and volume changes around these corporate events. In contrast to PAs and ARAs, his results question the information content hypothesis of AGMs: he finds that AGMs do not appear to give an above-average level of information. However, as noted by Olibe (2002), the use of weekly stock data may partly explain the lack of evidence supporting the informational role of AGMs, especially the exact duration of price and volume responses. In addition, Firth restricts his sample data to only 120 randomly selected UK firms and draws conclusion from estimates from the market model only.

Rippington and Taffler (1995) examine the same issue using a much larger sample of 337 firms for the period (May) 1979 to (June) 1981. Compared to both preliminary announcements and interim statements, their result shows that AGMs appear to convey relatively little information. The result remains the same even for small firms for which an AGM is more likely to be a major means of communication given their relatively limited coverage by equity analysts and institutional investors. However, investigating the information 
content of AGMs in the US for 100 randomly selected firms over the period 1978-82, Brickley (1986) finds positive abnormal return around AGMs thus supporting the informational role of AGMs. Brickley explains the result in the context of the finding by Kalay and Loewenstein (1985) who argue that significant increase in risk and return occurs around predictable information-producing events such as AGMs.

Olibe (2002) examines the inter-market role of AGMs using a sample of 227 UK firmyear observations covering the period 1994-1998. In particular, the author examines whether UK-based AGMs have information content in the US stock market. Using abnormal return and abnormal volume as proxies for information content, he finds that on the basis of abnormal return, US market participants find AGMs informative. In contrast, his results do not support a significant abnormal volume reaction to the information emanating from AGMs.

Given the likely impact of institutional variables, in particular investor protection and legal systems, on corporate governance measures and outcomes (La Porta et al., 1998), a number of studies examine whether the informational role of AGMs is evident in countries with different regulatory and economic environment from that of the US and the UK. In line with this strand of studies, García-Blandón et al. (2012) investigate the effect of AGMs on stock returns, volatility and trading volume in Spanish stock market. They find that AGMs do not have a significant effect on any of their three proxies for information content and conclude that no incrementally relevant information seems to be released to the market during AGMs. They find no significant difference in their reported results for blue chip and non-blue chip companies two groups of companies with different information environment. The result seems to question the informational and corporate governance roles of AGMs outside the UK and the US (see also, García-Blandón et al., 2011). Martinez-Blasco et al. (2015) assess the release of valuerelevant information during AGMs in particular whether there are differences in their impact on returns, returns volatility and trading volume in common law countries (UK and US) and 
civil-law countries (Germany, Japan, France and Spain). In general, the authors find no evidence in support of information content of AGMs for common and civil-law countries other than Germany. However, their sample of 1,148 observations is biased in favour of the largest firms in the countries studied.

Dimitrov and Jain (2011) provide the contexts for the value relevance of annual general meetings. The authors argue that management have the motivation to provide value relevant information during days before the annual general meeting in order to address potential concerns by shareholders on issues such as corporate performance, governance and management proposals. They suggest the possibility of management influencing the expectation of shareholders by, for example, borrowing good news from the future and delaying bad news until the annual general meeting. Their analysis of earnings announcement and management forecast announcement for a sample of US AGMs events provides evidence of significantly positive average cumulative abnormal returns (CARs) during the 40 days before the annual general meeting, consistent with the information content hypothesis of earnings announcement.

The present study is also related to studies examining the evolution of information content of corporate events. For example, Landsman and Maydew (2002) examine the information content of quarterly announcements over three decades (1972 to 1998) in the US and find that both abnormal return variance and abnormal trading volume surrounding earnings announcements have increased significantly. In a related study, Truong (2012) examines the evolution of the information content of earnings announcement in New Zealand and provides evidence that both abnormal return variance and abnormal trading volume around semi-annual earnings announcement dates increased gradually between 1994 and 2009. The result holds for both interim and preliminary earnings announcements. Finally, while our study is related to the studies by Wang and Hefner (2014) and Lawal (2016), it differs from theirs as we examine the 
information content of AGMs but do not propose or test a stock return anomaly associated with AGMs.

In summary, our review of the literature suggests some limitations and gaps in extant studies relating to the information content of AGMs. Firstly, these studies draw evidence from data drawn over a short period of time and for a limited amount of companies, thus limiting the temporal and cross-sectional qualities of the data and the opportunity to provide plausible explanations for the observed price and volume reactions around AGMs. In fact, we note that all the studies on this issue rely solely on descriptive analysis of abnormal return and abnormal volume derived from event studies. Secondly, none of the studies examine the evolution of the information content of AGMs, an important issue given the advancement in information technology and the resulting increase in sources of corporate information that may suggest less market reliance on AGMs. We address these concerns in this study.

\section{SAMPLE AND METHODOLOGY}

\subsection{Sample Selection}

The study population for the event study consists of all UK listed firms for the period 2004 to 2014. The event study sample is restricted to firm-years for which AGMs dates are available. In addition, we initially require firms included in the event study sample to have stock data necessary to calculate abnormal return and abnormal volume, our proxies for the information content of AGMs. As we are unaware of any database of UK annual general meetings, we hand-collected AGMs data from various sources: annual reports, notices of annual meetings, investors' relation pages and internet searches. Our data collection efforts resulted in 15,369 AGM dates (see Table 1). Extant studies on the information content of AGMs fail to account for the impact of confounding events on their results (see, for example, Olibe, 2002). To address the issue we identified contaminating events, such as directorate change, earnings and 
dividend announcements occurring during the specified event windows, from the Regulatory News System of the London Stock Exchange. In all, we excluded 556 AGM dates as a result of confounding events leaving us with a balance of 14,813 clean AGM events. We further matched our clean AGM dataset with stock and financial data from Datastream using the International Securities Identification Number (ISIN). Thus, we are able to mitigate the possible incidence of missing data or mismatching due, for example, to a change of company name. To avoid the problems associated with nonsynchronous or thin trading in event studies, we required all firm-events to not have more than 50 missing returns (volume) during the combined event and estimation windows. Our final event study sample consists of 14,533 and 13,607 AGM dates for the returns and volume event studies, respectively. The second stage regression analysis is restricted to firms with financial data on Datastream that enables the construction of the explanatory variables. As a result, the second stage regression samples consist of 4839 and 4133 observations for abnormal return and abnormal volume analyses, respectively.

Insert Table 1 about here

\subsection{Measurement of Information Content of Annual General Meetings}

Following extant literature (e.g. Firth, 1981), we define information content as the abnormal movements in security returns and volume (number of shares, number of trades and value of shares traded). In addition, following the classical Brown and Warner (1985) event study 
methodology, we compute abnormal return as the difference between actual return and expected return, where expected return is defined as normal return without conditioning on the AGM event. That is, abnormal return for stock $i$ on day $t$ is expressed as:

$$
A R_{i t}=R_{i t}-E\left(R_{i t} \mid X_{t}\right)
$$

where $A R_{i t}$ is the abnormal return of stock $i$ on day $t ; R_{i t}$ is the actual return of stock $i$ on day $t ; E\left(R_{i t} \mid X_{t}\right)$ is the expected return of stock $i$ on day $t . X_{t}$ is the conditioning information set for the normal return model. Expected return is computed using the market model:

$$
R_{i t}=\hat{\alpha}+\hat{\beta} R m_{i t}
$$

where $\hat{\alpha}$ and $\hat{\beta}$ are the estimated parameters of the market model; $R m_{i t}$ is the return on the market index. ${ }^{2}$ That is:

$$
A R_{i t}=R_{i t}-\left(\hat{\alpha}+\hat{\beta} R m_{i t}\right)
$$

Actual or realised stock return $\left(R_{i t}\right)$ is computed using the logarithmic return. We use the return on FTSE All Price Index as a proxy for market return. We estimate the parameters of the market model for each security (event) by taking the period 110 to 11 days before the AGM as reference. ${ }^{3}$ Consequently, we define the event window as the interval -10 and 10 , relative to the event day (0). Our choice of a 10 day period before the AGM accounts for the fact that, by law, the notice of meeting should be sent to shareholders at least 21 days before the AGM (Section 307 (2)(a) Companies Act 2006). This requirement suggests a possible leakage of information prior to the meeting which may explain insignificant abnormal return during the event window. The choice of this relatively long event window also allows us to examine how fast the market reflects the information, if any, in AGM as well as the day, relative to the event day, on which the market reacts (Menendez-Requejo, 2005). 
Therefore, for a sample of N AGM observations, we estimate the cross-sectional average abnormal return (AAR) for period $t$ as:

$$
A A R_{t}=\frac{1}{N} \sum_{i=1}^{N} A R_{i t}
$$

Cumulative average abnormal return (CAAR) is then computed as:

$$
C A A R_{b}=\sum_{i=a}^{b} A A R_{t}
$$

A statistically significant cumulative average abnormal return of zero is consistent with the null hypothesis of no information content of AGM. Alternatively, however, in view of the fact that an AGM event is a collection of a number of potentially value-relevant decisions which may contain both positive and negative news, a cumulative average abnormal return of zero is also consistent with a cancelling out of these effects leaving stock price unchanged. Conversely, any significant deviation from a mean value of zero is consistent with AGM signalling information to the market. In particular, a positive (negative) market reaction will be consistent with positive (negative) news from the AGM overriding negative (positive) news. Therefore, while a cumulative average abnormal return of zero is not clear evidence against the information content hypothesis of AGM, a positive (negative) reaction provides a clearer signal of the role of the AGM. We test for the significance of abnormal return using parametric time series test (Brown and Warner, 1985; Dyckman et al., 1984) and Patell (1976) Z statistic. ${ }^{4}$ However, past studies (e.g. Fama, 1976) suggest that daily returns do not follow a normal distribution, an important assumption underlying parametric tests. Therefore, we also provide results of the test of significance of abnormal return using the Corrado (1989) non-parametric rank test. ${ }^{5}$ We use the commercially available Event Study Metrics (Version 1.06) to calculate and test for statistical significance of abnormal return. 
It is possible that our estimates of abnormal return are sensitive to our choice of return generating process and of the estimation window. In particular, since shareholder meetings are predictable information-producing events, there is a high likelihood of significant movements in the stock prices (returns) before the events. In addition and consistent with the argument outlined in Dimitrov and Jain (2011), management of firms seem to provide price sensitive positive information before annual general meetings. This argument suggests the possibility that our estimates of beta coefficient of the market model are biased. To mitigate this concern and provide robustness checks of our results, we also estimate abnormal returns using the market return model. ${ }^{6}$ Specifically, abnormal returns are calculated by subtracting the contemporaneous return of a market index from stock return:

$$
A R_{i t}=R_{i t}-R m_{i t}
$$

All variables are as previously defined. This model can be viewed as the restricted market model with alpha equal to zero and beta equal to 1 for each firm-event.

In addition, and following Dimitrov and Jain (2011), we also examine different specifications of the estimation and event windows. In particular, we estimate the coefficient of the market model using days -140 and -41 as well as days +41 and +140 relative to the event day as estimation periods. The event windows are then specified as days -40 to $40,-40$ to 0 and 1 to 40. This allows us to re-examine the evidence provided by Dimitrov and Jain (2011) in the context of the UK and for a different study period.

Following Womack (1996) and Menendez-Requejo (2005), for each day of the event window $(-10,+10)$, we calculate abnormal volume $\left(A V_{i t}\right)$, our second proxy for information content, as the ratio of trade volume on day $t\left(V_{i t}\right)$ and the average volume over a 120-day estimation window, excluding the 21 day event window. That is: 


$$
A V_{i t}=\frac{V_{i t}}{\left(\sum_{=-70}^{-11} V_{i t}+\sum_{=70}^{11} V_{i t}\right) * 1 / 120}
$$

A ratio of 1.0 is interpreted as normal volume. Conversely, a ratio above (below) 1.0 is interpreted as positive (negative) abnormal volume. The average abnormal volume (AAV) for day $t$ is calculated for the whole sample as:

$$
A A V_{t}=\frac{1}{N} \sum_{i=1}^{N} A V_{i t}
$$

The cumulative average abnormal volume (CAAV) is then computed by adding the average daily abnormal volume over the event window:

$$
C A A V_{b}=\sum_{i=a}^{b} A A V_{t}
$$

\subsection{Explanatory Variables}

We examine the evolution in the information content of AGMs. However, as it the possible that an observed change in the magnitude of information content of AGMs may be due to changes in the composition of the sample over time, we also control for several firm characteristics. The explanatory variables capture the information environment of firms hypothesised to explain the informativeness of AGMs as well as factors which the literature suggests affect the variability of returns. Our discussion of the motivation and expected result for each of the explanatory variables follows. 


\section{Time Trend}

We construct a time variable that takes the value of 1 to 11 across years 2004-2014. We then regress the absolute values of our measures of the information content of AGMs against the time variable to establish whether the information content of AGMs has been increasing or decreasing during the study period. A significantly positive (negative) coefficient on the time variable is consistent with an increase (decrease) in the information content of AGM over the study period.

\section{Firm Size}

The information content of AGM should be related to firm size for a number of reasons. First, large firms usually receive more attention from market participants such as equity analysts and investors, thus reducing the informational value of corporate events (Christensen and Prabhala, 1995; Amihud and Li, 2006). In addition, Atiase (1985) and Rippington and Taffler (1995) suggest that the amount of pre-disclosed information is positively associated with firm size as larger firms often have richer information environment. Finally, firm size is also positively related to firm age, suggesting that investors have more information about the firm (Amihud and $\mathrm{Li}, 2006$ ). Following these arguments, we expect a negative relationship between firm size and the information content of AGMs. We measure firm size as the natural logarithm of the market capitalisation of the firm at the end of the financial year preceding the year of the AGM.

\section{Idiosyncratic Volatility and Beta}

Following Truong (2012) we also include a measure of firm idiosyncratic risk. Roll (1988) suggests that stock price volatility is a function of the amount of firm-level relative to marketlevel information incorporated in stock prices. The higher the level of firm-specific information relative to market-specific information the higher the increase in firm-specific stock price volatility. Campbell et al. (2001) suggest that an increase in idiosyncratic stock volatility is evidence of increasing stock price informativeness. We measure idiosyncratic volatility as the 
residual variance from the regression of stock returns on market returns over a period of 48 months preceding the month of the AGM. Following Truong (2012) we also include the beta value from the regression as an additional control variable. We expect a positive relationship between idiosyncratic risk (beta) and the information content of AGMs.

\section{Number of Analysts Following}

Firms followed by more financial analysts are likely to have more publicly available information (Bhushan, 1994). We include a variable that captures the degree of analysts following defined as the number of financial analysts providing one-year-ahead earnings forecasts for firms. We use data variable EPS1NET - the number of analysts providing one year ahead EPS forecast - provided by International Brokers Estimate System (I/B/E/S) to construct this variable. The stock prices of firms with large analyst following are more likely to incorporate firm-specific information released before the AGMs. Therefore, firms with large analysts following are likely to experience a weaker market reaction to information emanating from AGMs. Thus, we expect a negative relationship between abnormal return (volume) and analysts following.

\section{Stock Liquidity}

A number of arguments suggest that stock liquidity affects stock prices and by extension market reaction to corporate events. High stock liquidity is associated with low transaction cost, implying that it is less costly to trade on new and relevant information (Truong, 2012). This argument suggests a positive relationship between stock liquidity and the market reaction to AGMs. An alternative argument suggests that firms whose stocks are highly liquid are less informationally opaque than firms with low stock liquidity. Therefore, AGMs of firms with high stock liquidity are less likely to convey new value relevant information. In addition, empirical evidence suggests that trades have a lower price impact when markets are more liquid 
(see, for example, LaPlante and Muscarella, 1997). Following these alternative arguments, we expect a negative relationship between stock liquidity and the market reaction to AGMs. We measure stock liquidity as the ratio of the average value of stock traded to the average value of shares outstanding (market capitalisation) over the period of one year preceding the year of the AGM.

\section{EMPIRICAL RESULTS}

\subsection{Information Content of Annual General Meetings}

Figure 1 plots the average abnormal returns (AARs) and the cumulative average abnormal returns (CAARs). Consistent with the information content hypothesis, the figure provides evidence of significant downward movements in AARs and CAARs during the 21-day event window. This patterns seems to extend at least until day -40 relative to the annual general meeting day as shown in Figure 2. However, the market seems to react significantly positively to AGMs on the event day (day 0). Table 2 presents the tests of significance of AARs and CAARs. In support of the information content hypothesis, abnormal returns are statistically significant on 10 days of the 21-day event window and 2 days of the shorter 3-day window. The highest absolute abnormal return is reported on event day 0 . The results support a significantly positive market reaction of an average of $0.15 \%$ (t-value $=3.11)$ on AGM dates. This evidence, however, contradicts the result reported by Martinez-Blasco et al. (2015) who find no evidence of stock price response to AGMs on event dates.

The cumulative abnormal returns are significantly negative over the 21 -day event window. AGMs are associated with a statistically significant reduction of about $0.64 \%$ in share price over this period ( $\mathrm{t}$-value $=-10.42$ ). This result holds whether we use the parametric $\mathrm{t}$-test or the non-parametric (Corrado, 1989) test. However, the results presented in Table 2 suggest a positive abnormal return for the narrower multi-day event windows of between two to three 
days: the abnormal return for the 2 -day event window ( -1 to 0$)$ is about $0.16 \%(z$-value $=2.82)$. The change in the direction of abnormal returns between the event and non-event windows suggest changes in risk and return consistent with release of relevant information around predictable events (Kalay and Loewenstein, 1985).

Panel $\mathrm{C}$ of Table 2 also presents the results of the estimation of the abnormal returns using the market model and an estimation period of -140 to -41 relative to the event date. In this case, we have presented only the cumulative average abnormal returns for the purpose of brevity. Our results are consistent with the overall negative abnormal returns reported in Panel A of the table. However, these results are contrary in magnitude and sign (direction) to those reported by Dimitrov and Jain (2011). Specifically, our results do not support the idea that management of UK firms delay negative news and/or bring forward positive news before the annual general meetings. Our conclusion, however, seems to be sensitive to the choice of estimation window as we find significantly positive abnormal returns over a longer event window [-40 to 40] and in particular the period before the annual general meeting [-40 to 0$]$ when we specify the estimation period as +41 and +140 days relative to the day of the annual general meeting (see Panel D of Table 2).

Table 3 presents the results of the estimation of abnormal returns using the market return model as described in Section 3 of this paper. The results are generally consistent with significantly negative market reactions before and after annual general meetings. The difference between our results and those reported by Damitrov and Jain (2011) is therefore not due to any difference in our assumed return generating process. In addition, the result reported in Table 3 are independent of the choice of our estimation and event windows: the sign and magnitude of abnormal returns are generally similar. 


\section{Insert Figure 1 about here}

\section{Insert Table 2 about here}

Figure 2 plots the average abnormal volume by number of traded shares, value of traded shares and number of trades around AGMs. The recurring picture in the figure is that the volume of trades during the event window is greater than the average volume for the 120-day estimation window, inclusive of dates before and after the AGMs. The market reaction is particularly significant around days 0 and +1 .

Insert Figure 2 about here

Table 4 presents the results of the tests of average abnormal volume for the event window ($10,+10)$. Taking into account that the normal volume is 1 while values above 1 suggest volume superior to normal volume and vice versa, the evidence suggests statistically significant positive volume reaction at different days during the event window. The standout evidence is, 
however, the significantly positive market reaction for all measures of abnormal volume for each of the specified event window including pre-meeting dates (-40 to 0$)$ and post-meeting dates ( 1 to 40$)$. For example, the value of trades on the event day (0) is $68 \%$, significantly higher $(\mathrm{t}$-value $=11.68)$ than the average $($ normal $)$ value of trades consistent with the release of value relevant information on this day. This result is contrary to that reported in GarcíaBlandón et al. (2012) who find that shareholder meetings do not seem to have any effect on trading volume in Spain. The results of our volume analysis of number of trades, numbers of shares and value of trades seem to support the positive abnormal returns during pre-meeting dates uncovered by Dimitrov and Jain (2011). Their study, however, does not investigate abnormal volumes around annual general meetings.

\section{Insert Table 3 about here}

\subsection{Changes in the Information Content of Annual General Meetings}

The results presented so far relate to the information content hypothesis of AGMs but do not address the question regarding a change in the information content of AGMs over the period of the study. We address this question in this section. In line with similar studies examining time trend in the information content, we infer an increase (or a decrease) in abnormal return and abnormal volume as evidence of an increase (or a decrease) in the information content of AGMs (Landsman and Maydew, 2002; Truong, 2012).

We start our analysis by regressing the yearly mean abnormal returns (or abnormal volume) on a time trend. The unreported result suggests no evidence of a time trend in the information content of AGMs. The result remains the same even after using the absolute value of abnormal 
return and abnormal volume. As this result may be due to the limited number of years, we further investigate the idea of a change in the information content of AGMs using level and interaction variables at the firm level. Table 5 presents the results from the estimation of the model relating information content of AGMs to the trend variable and other control variables discussed above. In order to mitigate the possible effects of outliers, we winsorise the dependent variables - abnormal returns and abnormal volume - at the $1 \%$ and $99 \%$ levels. The reported t-statistics are based on standard errors corrected for heteroscedasticity using the Hubber-White procedure and clustered at firm level. Table 1 of this paper provides some evidence of monthly clustering of annual general meeting. Therefore, we include month fixed effects to account for the possible influence of clustering of AGMs on returns as reported by Lawal (2016) and Wang and Warner (2014). We find no evidence that the results presented in Table 5 are driven by clustering of annual general meetings. None of the coefficients of the monthly dummy variables are significant at the required levels.

The coefficient on the trend variable is significantly positive (t-value $=2.5)$ in the model in which abnormal return is the dependent variable. Thus, there is strong evidence that information content of $\mathrm{AGM}$ as proxied by abnormal return seems to have increased significantly over time. However, we find no evidence of an increasing or reducing information content using abnormal volume as a proxy - the coefficient on the time variable is not significantly different from zero. The result suggests that changes in the information content of AGMs are reflected in stock returns rather than in trading volume.

Columns 2 and 4 include firm characteristics hypothesised to explain abnormal return and abnormal volume around AGMs as well as the interaction variables which examine whether the change in the information content of AGMs, if any, depends on changes in the factors characterising the information environment of firms. Column 2 presents the result where abnormal return is the dependent variable while Column 4 presents the analogous result for 
abnormal volume. The coefficient on the time variable continues to be significantly positive in the abnormal return regression $(\mathrm{t}$-value $=3.63)$ even after controlling for firm characteristics. This result suggests that the relevance of AGMs seems to have increased during the period covered by this study. In general, the firm characteristics included in the regressions appear to be significantly related to the information content of AGMs. The coefficient on the size variable is significantly positive ( $\mathrm{t}$-value $=2.69$ ) suggesting that larger firms experience greater abnormal return around AGMs dates than smaller firms. This is inconsistent with the argument that larger firms have more pre-disclosed information and should, therefore, benefit less from value-relevant information at AGMs.

We find no evidence that firms idiosyncratic volatility is related to the market reaction to AGMs. The coefficient on idiosyncratic risk is insignificant suggesting that firms with high or low idiosyncratic volatility do not react in a significantly distinguishable manner to AGMs. The variables capturing the number of analysts coverage analyst following and stock liquidity load significantly negatively. The negative coefficient on analyst following (t-value $=-2.76$ ) supports the idea that public information is more easily available for firms with greater analysts following resulting in a less profound price reaction to AGMs for these firms. The negative coefficient on the stock liquidity variable $(\mathrm{t}$-value $=-1.92)$ is a rejection of the transaction cost argument which suggests that investors of firms with highly liquid stock incur lower transaction cost and are therefore more likely to act on new and relevant information from AGMs. The result supports the alternative argument which suggests that liquid stocks have a lower price impact.

The significance of many of the interaction variables in the abnormal return regression also suggests that the increase in the information content of AGMs reported in this study depends on firm characteristics. The interaction variable for time and size is significantly negative ( $t-$ value $=-2.20$ ). This implies that an increase in the information content of AGMs is less 
pronounced for larger firms relative to smaller firms. The interaction variable for time and stock liquidity is highly significantly positive ( $\mathrm{t}$-value $=3.18$ ) suggesting the change in the information content of AGMs is more positive for firms with highly liquid stocks. The result of the interaction of the time variable with the number of analysts following is consistent with firms with more analysts following experiencing a greater positive change in the information content of AGMs during the period. The coefficient on time and analyst following interaction variable is significantly positive $(\mathrm{t}$-value $=2.05)$ suggesting that information released during AGMs by firms with greater analysts following is more value relevant. We also find that the improvement in the information content of AGMs is less pronounced for firms with greater systematic risk - the coefficient on the time and systematic risk interaction is statistically negatively significant $(\mathrm{t}$-value $=-3.15)$.

Columns 2 and 4 of Table 5 report the results of the regressions in which abnormal volume (value of trades) is the dependent variable. Contrary to the evidence of a temporal change in information content from our aanlysis of abnormal returns, we find no evidence of a change in the information content of AGMs from our analysis of abnormal volume. The result remains the same for alternative models using abnormal number of shares and number of trades (unreported). The result is, however, consistent with the literature as the assessment of the information content of corporate events from the analysis of returns and volume sometimes provide contradictory results (see, for example, Olibe 2002).

\section{Insert Table 4 about here}




\section{SUMMARY AND CONCLUSION}

In this study, we examine the information content of AGMs using event study methodology. Our results support the information content hypothesis using both abnormal return and abnormal volume as proxies for information content. AGMs are associated with a significantly negative abnormal return for various specifications of event windows, estimation windows and return generation processes. This negative market reaction is however tempered by a significantly positive market reaction during a narrower 3-day event window. In general, we find significantly positive volume reactions to AGMs, especially during the narrow 3-day event window. This result remains the same whatever the definition of abnormal volume we use.

Our study is the first to examine the evolution of the information content of AGMs in the UK. We find some evidence from the analysis of abnormal return suggesting an increase in the information content of AGMs in the last decade. This result suggests that the increase in the alternative mandatory and non-mandatory sources of information does not seem to have reduced the importance of AGMs to investors. However, we fail to find support for a change in the information content of AGMs from our analysis of abnormal volumes, whatever the measures adopted. This result is however not surprising as the empirical literature often report contradicting evidence on the information content of corporate event using both returns and volume analyses. Overall, our results support not only the relevance of AGMs but also their increasing relevance as a communication tool that helps in promoting an efficient price discovery. 
The evidence presented in this paper is however limited to the UK. As a result, we suggest that future studies should consider whether these results are applicable to other countries with similar (e.g. the US) or different (e.g. Japan) institutional environment as that of the UK. In addition to the firm-specific factors considered in our study, it would be interesting to understand the role, if any, of institutional factors in the evolution of AGMs. In line, with this, future studies should consider, for example, whether differences in investor protection, the degree of institutional holding, quality of accounting, and legal systems impact the information content of AGMs and its evolution thereof. Finally, our study does not examine extraordinary general meetings (EGMs). Given the place of EGMs in examining serious and urgent issues requiring shareholders' attention and approval before the AGM, it would be interesting to know whether EGMs convey information to investors and in particular whether the market reacts more strongly to EGMs compared to AGMs. 
Notes

1. A growing number of companies now convene meetings with their largest shareholders or host the so-called 'fifth analyst calls' to engage with many shareholders on governance issues. These calls and meetings generally occur prior to the AGM. In addition, the Companies Act 2006 now supports and provides the legal framework for the use of companies' websites to communicate information to shareholders.

2. The ordinary least squares method was used in estimating the parameters of the market model. However, the results were qualitatively the same using Scholes and Williams' (1977) method to account for the potential impact of non-synchronous trading.

3. Armitage (1995) suggests using estimation windows of between 100 to 300 days for daily observations.

4. See Armitage (1995) for a description of these tests.

5. The author suggests that the rank test has more power to detect abnormal price changes than standard parametric tests.

6. We thank the anonymous reviewer of this paper for their comment and recommendation. 


\section{References}

Amihud, Y and Li, K.. (2006) 'The declining information content of dividend announcements and the effects of institutional holdings', Journal of Financial and Quantitative Analysis, Vol. 41, No. 3, pp.637 - 660 .

Armitage, S. (1995) 'Event study methods and evidence on their performance', Journal of Economic Surveys, Vol. 9, No. 1, pp.25 - 52.

Atiase, R.K. (1985) 'Predisclosure information, firm capitalization, and security price behavior around earnings announcements', Journal of Accounting Research, Vol. 23, No. 1, pp.21-36.

Beaver, W.H. (1968) 'The information content of annual earnings announcements', Journal of Accounting Research, Supplement 6, pp.67 - 92.

Bhushan, R. (1994) 'An informational efficiency perspective on the post-earnings announcement drift', Journal of Accounting and Economics, Vol. 18, No. 1, pp.45 - 65.

Brickley, J.A. (1986) 'Interpreting common stock returns around proxy statement disclosures and annual shareholder meetings', Journal of Financial and Quantitative Analysis, Vol. 21, No. 3, pp.343 - 349.

Brown, S.J. and Warner, J.B. (1985) 'Using daily stock returns: the case of event studies', Journal of Financial Economics, Vol. 14, No. 1, pp.3 - 31.

Campbell, J.Y., Lettau, M., Malkiel, B. G. and Xu, Y. (2001) 'Have individual stocks become more volatile? An empirical exploration of idiosyncratic risk', Journal of Finance, Vol. 56, No. 1, pp. $1-43$.

Chen, H., Nguyen, H.H. and Singal, V. (2011) 'The information content of stock splits', Journal of Banking \& Finance, Vol. 35, No. 9, pp.2454 - 2467.

Christensen, B. and Prabhala N.R. (1995) 'Expectation and the cross-section of dividend announcement effects', Working Paper, New York Univ.

Corrado, C.J. (1989) 'A nonparametric test for abnormal security-price performance in event Studies', Journal of Financial Economics, Vol. 23, No. 2, pp.385 - 395.

Denis, D.J., Denis, D.K. and Sarin, A. (1994) 'The information content of dividend changes: cash flow signaling, overinvestment, and dividend clienteles', Journal of Financial and Quantitative Analysis, Vol. 29, No. 4, pp.567 - 587.

Dimitrov, V and Jain P.C. (2011) 'It's showtime: Do managers report better news before annual shareholders meetings? Journal of Accounting Research, Vol 49, pp.1193-1221

Dyckman, T., Philbrick, D. and Stephan, J. (1984) 'A comparison of event study methodologies using daily stock returns: a simulation approach', Journal of Accounting Research, Vol. 22, pp.1 30.

Fama, E.F. (1976). Foundation of Finance. Basic Books, New York.

Financial Reporting Council. (2014) The UK Corporate Governance Code.

https://frc.org.uk/Our-Work/Publications/Corporate-Governance/UK-Corporate-Governance-Code2014.pdf. (Accessed 1 March 2016).

Firth, M. (1981) 'The relative information content of the release of financial results data by firms', Journal of Accounting Research, Vol. 19, No. 2, pp.521 - 529.

García-Blandón, J., Blasco, M.M. and Bosch, J.M. (2011) 'The Role of Annual General Meetings in a Civil-Law Country. In International Corporate Governance (Advances in Financial Economics) Kose, J., \& Makhija, A. K. (Eds.). Vol. 14. UK: Emerald Group Publishing Limited.

García-Blandón, J., Blasco M.M. and Sabate L.G. (2012) 'Does the annual general meeting involve the release of relevant information in non-common law markets? Evidence from Spain'. Spanish Journal of Finance and Accounting/Revista Española de Financiación Y Contabilidad, Vol. 41, No. 154, pp.209 - 232.

Kalay, A. and Loewenstein, U. (1985) 'Predictable events and excess returns: the case of dividend announcements', Journal of Financial Economics, Vol. 14, No. 3, pp.423 - 449.

Kim, O. and Verrecchia, R.E.. (1991) 'Trading volume and price reactions to public announcements', Journal of Accounting Research, Vol. 29, No. 2, pp.302 - 321. 
Kyle, A.S. (1985) 'Continuous auctions and insider trading', Econometrica: Journal of the Econometric Society, Vol. 53, No. 2, pp.1315 - 1335.

La Porta, R., Lopez-de-Silanes, F., Shleifer A. and Vishny, R.W. (1998) 'Law and finance'. Journal of Political Economy, Vol. 106, pp.1113 - 1155.

Landsman, W.R. and Maydew, E.L. (2002) 'Has the information content of quarterly earnings announcements declined in the past three decades?', Journal of Accounting Research, Vol. 40, No. 3, pp.797 - 808.

LaPlante, M. and Muscarella, C.J. (1997) 'Do institutions receive comparable execution in the NYSE and NASDAQ markets? A Transaction Study of Block Trades', Journal of Financial Economics, Vol. 45, No. 1, pp.97 - 134.

Lawal, T. (2016) 'Clustering of annual general meetings and stock returns: UK evidence', Journal of Behavioral and Experimental Finance, Vol. 11, pp.9 -12.

Martínez-Blasco, M, Garcia-Blandon, J. and Argiles-Bosch, J.A. (2015) 'Does the informational role of the annual general meeting depend on a country's legal tradition?', Journal of Management \& Governance, Vol. 19, No. 4, pp.849 - 873.

Menendez-Requejo, S. (2005) 'Market valuation of the analysts' recommendations: the Spanish stock market', Applied Financial Economics, Vol. 15, No. 7, pp.509 - 518.

Olibe, K.O. (2002) 'The information content of annual general meetings: a price and trading volume analysis', Journal of International Accounting, Auditing and Taxation, Vol. 11, No. 1, pp.19 37.

Patell, J.M. (1976) 'Corporate forecasts of earnings per share and stock price behavior: empirical test', Journal of Accounting Research, Vol. 14, No. 2, pp.246 - 276.

Rippington, F.A. and Taffler, R.J. (1995) 'The information content of firm financial disclosures', Journal of Business Finance \& Accounting, Vol. 22, No. 3, pp.345 - 362.

Roll, R. (1988) 'Presidential Address: R2', Journal of Finance, Vol. 43, No. 2, pp. 541 - 566.

Scholes, M. and Williams, J. (1977) 'Estimating betas from nonsynchronous data', Journal of Financial Economics, Vol. 5, No. 3, pp.309 - 327.

Strätling, R. (2003) 'General meetings: a dispensable tool for corporate governance of listed companies?' Corporate Governance: An International Review, Vol. 11, No. 1, pp.74 - 82.

Truong, C. (2012) 'Information content of earnings announcements in the New Zealand equity market, a longitudinal analysis', Accounting \& Finance, Vol. 52, No. s1, pp.403 - 432.

U.K. Parliament (2006) Companies Act 2006 https://www.legislation.gov.uk/ukpga/2006/46/pdfs/ukpga_20060046_en.pdf (Accessed 30 April 2016).

Wang, W. and Hefner, F. (2014) 'Clustering of shareholder annual meetings: a "new anomaly" in stock returns', Applied Financial Economics, Vol. 24, No. 16, pp.1103 - 1110.

Warner, J.B., Watts, R.L. and Wruck, K.W. (1988) 'Stock prices and top management changes', Journal of Financial Economics, Vol. 20, pp.461 - 492.

Womack, K.L. (1996) 'Do brokerage analysts' recommendations have investment value?', Journal of Finance, Vol. 51, No. 1, pp.137 - 16 
TABLE 1

Distribution of Annual General Meetings

\begin{tabular}{|c|c|c|c|}
\hline \multirow[t]{2}{*}{ Calendar Year } & \multirow{2}{*}{$\begin{array}{l}\text { AGMs in } \\
\text { Database }\end{array}$} & \multicolumn{2}{|c|}{ Event Study Sample } \\
\hline & & Returns & Volume \\
\hline \multicolumn{4}{|c|}{ Panel A: Yearly Distribution of Annual General Meetings } \\
\hline 2004 & 611 & 560 & 497 \\
\hline 2005 & 771 & 720 & 579 \\
\hline 2006 & 957 & 888 & 865 \\
\hline 2007 & 1161 & 1091 & 1056 \\
\hline 2008 & 1436 & 1364 & 1305 \\
\hline 2009 & 1512 & 1442 & 1210 \\
\hline 2010 & 1613 & 1535 & 1472 \\
\hline 2011 & 1701 & 1610 & 1550 \\
\hline 2012 & 1766 & 1687 & 1614 \\
\hline 2013 & 1870 & 1791 & 1703 \\
\hline 2014 & 1971 & 1845 & 1756 \\
\hline Total & 15369 & 14533 & 13607 \\
\hline \multicolumn{4}{|c|}{ Panel B: Monthly Distribution of Annual General Meetings } \\
\hline January & & 555 & 506 \\
\hline February & & 460 & 439 \\
\hline March & & 535 & 496 \\
\hline April & & 1211 & 1121 \\
\hline May & & 2924 & 2777 \\
\hline June & & 2219 & 2157 \\
\hline July & & 2137 & 1962 \\
\hline August & & 742 & 659 \\
\hline September & & 1262 & 1189 \\
\hline October & & 684 & 615 \\
\hline November & & 949 & 883 \\
\hline December & & 855 & 803 \\
\hline \multirow[t]{4}{*}{ Total } & & 14533 & 13607 \\
\hline & & \multirow{2}{*}{\multicolumn{2}{|c|}{$\begin{array}{l}\text { Longitudinal (Regression) } \\
\text { Analysis }\end{array}$}} \\
\hline & & & \\
\hline & & Returns & Volume \\
\hline 2004-2014 & 15369 & 4789 & 4133 \\
\hline
\end{tabular}

The table presents yearly and monthly distribution of annual general meeting dates for the period 2004-2014. AGM dates were hand-collected from various sources, including annual reports, notices of annual general meeting, investors' relations pages and internet searches. 


\section{TABLE 2}

\section{Average Abnormal Return and Cumulative Average Abnormal Return around}

Annual General Meetings

Panel A - Average Abnormal Returns and Cumulative Abnormal Returns.

\begin{tabular}{lllllllll}
\hline Days & $\begin{array}{l}\text { AAR } \\
(\%)\end{array}$ & $\begin{array}{l}\text { t- } \\
\text { statistic }\end{array}$ & $\begin{array}{l}\text { Positive } \\
(\%)\end{array}$ & $\begin{array}{l}\text { Corrado } \\
\text { (\%) }\end{array}$ & $\begin{array}{l}\text { CAAR } \\
(\%)\end{array}$ & $\begin{array}{l}\text { Positiv } \\
\text { e }(\%)\end{array}$ & $\begin{array}{l}\text { Z- } \\
\text { statistic }\end{array}$ & \\
\hline-10 & -0.01 & -0.58 & 50 & -0.37 & -0.01 & 50 & $-2.35^{* * *}$ & -0.37 \\
-9 & -0.01 & -0.24 & 50 & -1.23 & -0.02 & 49 & $-3.22^{* * *}$ & -1.13 \\
-8 & -0.09 & -1.44 & 50 & -0.61 & -0.11 & 49 & $-3.73^{* * *}$ & -1.28 \\
-7 & -0.02 & -0.79 & 50 & -0.46 & -0.13 & 48 & $-3.31^{* * *}$ & -1.33 \\
-6 & -0.06 & $-2.04^{* *}$ & 50 & -1.45 & -0.18 & 48 & $-5.20^{* * *}$ & $-1.84^{*}$ \\
-5 & 0 & -0.09 & 51 & 0.03 & -0.19 & 48 & $-5.36^{* * *}$ & $-1.67^{*}$ \\
-4 & 0.01 & 0.27 & 50 & -0.1 & -0.18 & 48 & $-5.43^{* * *}$ & -1.45 \\
-3 & -0.04 & $-1.89^{*}$ & 50 & -0.02 & -0.22 & 48 & $-5.72^{* * *}$ & -1.59 \\
-2 & -0.06 & $-2.36^{* *}$ & 50 & -0.67 & -0.28 & 48 & $-6.73^{* * *}$ & -1.54 \\
-1 & 0 & 0.05 & 51 & 0.71 & -0.28 & 48 & $-7.29^{* * *}$ & -1.28 \\
0 & 0.15 & $3.11^{* * *}$ & 54 & $5.03^{* * *}$ & -0.12 & 49 & $-4.19^{* * *}$ & 0.30 \\
1 & -0.07 & $-2.25^{* *}$ & 50 & $-1.81^{*}$ & -0.19 & 49 & $-5.12^{* * *}$ & -0.24 \\
2 & 0 & 0.02 & 49 & -0.82 & -0.19 & 49 & $-5.42^{* * *}$ & -0.46 \\
3 & -0.05 & 1.49 & 50 & -1.4 & -0.24 & 49 & $-5.72^{* * *}$ & -0.82 \\
4 & -0.11 & $-2.64^{* * *}$ & 49 & $-2.03^{* *}$ & -0.35 & 49 & $-6.60^{* * *}$ & -1.32 \\
5 & -0.02 & -0.53 & 49 & -1.54 & -0.37 & 48 & $-7.72^{* * *}$ & $-1.66^{*}$ \\
6 & -0.02 & -0.97 & 50 & -0.90 & -0.40 & 48 & $-8.12^{* * * *}$ & $-1.83^{*}$ \\
7 & -0.07 & $-2.87^{* * *}$ & 49 & -1.37 & -0.47 & 48 & $-8.83^{* * *}$ & $-2.10^{* *}$ \\
8 & -0.07 & $-3.04^{* * *}$ & 49 & -1.17 & -0.54 & 48 & $-9.59^{* * *}$ & $-2.31^{* *}$ \\
9 & -0.05 & $-2.01^{* *}$ & 50 & -0.57 & -0.59 & 48 & $-9.74^{* * *}$ & $-2.38^{* *}$ \\
10 & -0.05 & $-2.04^{* *}$ & 49 & $1.87^{*}$ & -0.64 & 47 & $-10.42^{* * *}$ & $-2.73^{* * *}$ \\
\hline & & & & & & & & \\
\hline
\end{tabular}

\begin{tabular}{|c|c|c|c|c|}
\hline \multicolumn{5}{|c|}{ Panel B Multi-day window } \\
\hline & CAAR $(\%)$ & $\%$ Positive & Z- & Corrado \\
\hline-1 to +1 & 009 & 52 & 132 & $227^{* *}$ \\
\hline-1 to 0 & 0.16 & 53 & $282^{* * *}$ & $406^{* * *}$ \\
\hline-1 to +2 & 0.09 & 51 & 1.30 & $1.66^{*}$ \\
\hline \multicolumn{5}{|c|}{ Panel C Multi-day window } \\
\hline & CAAR $(\%)$ & $\%$ Positive & $\begin{array}{c}\text { Z- } \\
\text { statistic }\end{array}$ & Corrado \\
\hline-40 to 40 & -1.65 & 47 & $-14.68^{* * *}$ & $-2.59^{* * *}$ \\
\hline-40 to 0 & -0.24 & 49 & $-7.17^{* * *}$ & 1.32 \\
\hline 1 to 40 & -1.41 & 45 & $-13.63^{* * *}$ & $-5.02^{* * *}$ \\
\hline \multicolumn{5}{|c|}{ Panel D Multi-day window } \\
\hline & CAAR (\%) & $\%$ Positive & Z-statistic & Corrado \\
\hline-40 to 40 & 0.83 & 49 & $7.84^{* * *}$ & $2.65^{* * *}$ \\
\hline-40 to 0 & 0.92 & 50 & $9.46^{* * *}$ & $3.08^{* * *}$ \\
\hline 1 to 40 & -0.09 & 48 & -1.57 & $-2.28^{* *}$ \\
\hline
\end{tabular}

Notes: The table presents price reaction around AGMs. AAR is the average abnormal return and CAAR is the cumulative average abnormal return. The averages were computed across 
firm-events. The cross sectional t-statistic (Brown and Warner, 1980) and Z- statistic (Patell 1976) report the test of the null hypothesis that AAR and CAAR are zero. Corrado is the Corrado (1989) non-parametric statistic. The sample consist of 14,533 handcollected AGM dates for the period 2004-2014. Abnormal (cumulative) returns are derived from the estimation of the market model for each firm-event in the sample. Results in Panel A and Panel B are estimates from the estimation window of -110 to 11 days relative to the event day. Results in Panel $\mathrm{C}$ and Panel D are estimates from estimation periods of -140 to -41 and +41 to +140 relative to the event day, respectively.

****indicates significant at $1 \%$,

**indicates significant at $5 \%$

*indicates significant at $10 \%$ 


\section{TABLE 3}

Average Abnormal Return and Cumulative Average Abnormal Return around Annual General Meetings

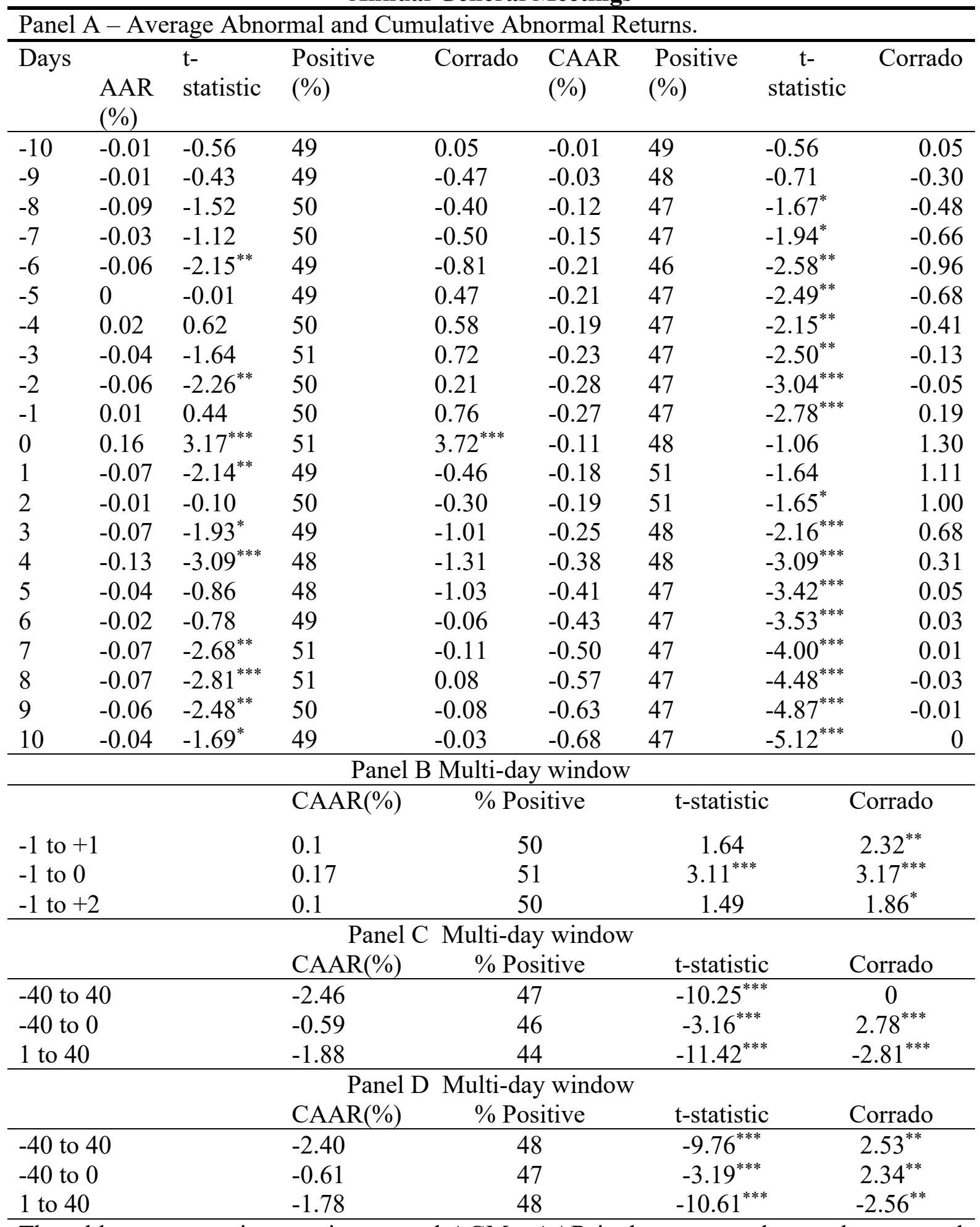

The table presents price reaction around AGMs. AAR is the average abnormal return and CAAR is the cumulative average abnormal return. The averages were computed across firm-events. The cross sectional t-statistic (Brown and Warner, 1980) reports 
the test of the null hypothesis that AAR and CAAR are zero. Corrado is the Corrado (1989) non-parametric statistic. The sample consist of 14, 533 hand-collected AGM dates for the period 2004-2014. Abnormal (cumulative) returns are derived from the estimation of the market return model for each firm-event in the sample. Results in Panel A and Panel B are estimates from the estimation window of -110 to 11 days relative to the event day. Results in Panel $\mathrm{C}$ and Panel $\mathrm{D}$ are estimates from estimation periods of, -140 to -41 and +41 to +140 days relative to the event day, respectively. T-statistics are reported for CAARs instead of $\mathrm{Z}$ - statistics.

*** indicates significant at $1 \%$.

** indicates significant at $5 \%$.

* indicates significant at $10 \%$. 
Table 4

Daily Abnormal Volume around Annual General Meetings

\begin{tabular}{|c|c|c|c|c|c|c|c|c|c|}
\hline Day & $\begin{array}{l}\text { Abn. } \\
\text { Vol } \\
\text { (shares) }\end{array}$ & $\begin{array}{l}\text { t- } \\
\text { statistic }\end{array}$ & Corrado & $\begin{array}{l}\text { Abn. } \\
\text { Vol. } \\
\text { (Value) }\end{array}$ & $\begin{array}{l}\text { t- } \\
\text { statistic }\end{array}$ & Corrado & $\begin{array}{l}\text { Abn } \\
\text { Vol } \\
\text { (trades) }\end{array}$ & t-statistic & Corrado \\
\hline-10 & 1.13 & $4.93^{* * *}$ & $-1.77^{*}$ & 1.12 & $4.77^{* * *}$ & $-1.73^{*}$ & 1.07 & $6.96^{* * *}$ & -1.53 \\
\hline-9 & 1.20 & $3.16^{* * *}$ & $-1.87^{*}$ & 1.22 & $3.81^{* * *}$ & $-1.73^{*}$ & 1.10 & $6.78^{* * *}$ & -1.58 \\
\hline-8 & 1.08 & $3.05^{* * *}$ & $-2.36^{* *}$ & 1.10 & $3.39^{* * *}$ & $-2.35^{* *}$ & 1.08 & $5.64^{* * *}$ & $-1.82^{*}$ \\
\hline-7 & 1.17 & $4.20^{* * *}$ & $-1.95^{*}$ & 1.19 & $4.36^{* * *}$ & $-1.83^{*}$ & 1.06 & $6.06^{* * *}$ & $-1.68^{*}$ \\
\hline-6 & 1.17 & $4.56^{* * *}$ & $-1.78^{*}$ & 1.23 & $4.97^{* * *}$ & $-1.71^{*}$ & 1.08 & $7.72^{* * *}$ & -1.43 \\
\hline-5 & 1.13 & $3.40^{* * *}$ & $-1.81^{*}$ & 1.14 & $3.22^{* * *}$ & $-1.70^{*}$ & 1.09 & $7.67^{* * *}$ & -1.55 \\
\hline-4 & 1.18 & $4.19^{* * * *}$ & $-1.70^{*}$ & 1.23 & $4.57^{* * *}$ & $-1.67^{*}$ & 1.10 & $7.68^{* * *}$ & -1.41 \\
\hline-3 & 1.20 & $3.24^{* * *}$ & $-2.01^{* *}$ & 1.19 & $3.48^{* * *}$ & $-1.95^{*}$ & 1.10 & $8.27^{* * *}$ & $-1.66^{*}$ \\
\hline-2 & 1.30 & $2.34^{* * *}$ & -1.63 & 1.25 & $3.24^{* * *}$ & -1.48 & 1.10 & $7.48^{* * *}$ & -1.28 \\
\hline-1 & 1.24 & $3.82^{* * *}$ & -0.99 & 1.34 & $4.31^{* * *}$ & -0.83 & 1.14 & $6.73^{* * *}$ & -0.81 \\
\hline 0 & 1.68 & $11.68^{* * *}$ & $2.89^{* * * *}$ & 1.74 & $8.22^{* * *}$ & $2.71^{* * *}$ & 1.46 & $28.19^{* * *}$ & $2.48^{* * *}$ \\
\hline 1 & 1.33 & $9.39^{* * *}$ & 0.55 & 1.38 & $8.38^{* * *}$ & 0.53 & 1.22 & $17.63^{* * *}$ & 0.40 \\
\hline 2 & 1.40 & $3.52^{* * *}$ & -0.61 & 1.46 & $3.41^{* * *}$ & -0.69 & 1.16 & $12.66^{* * *}$ & -0.47 \\
\hline 3 & 1.25 & $3.74^{* * *}$ & -1.17 & 1.27 & $3.44^{* * *}$ & -1.27 & 1.14 & $10.61^{* * *}$ & -0.68 \\
\hline 4 & 1.25 & $3.52^{* * *}$ & -1.06 & 1.23 & $3.53^{* * *}$ & -1.02 & 1.11 & $9.86^{* * *}$ & -0.76 \\
\hline 5 & 1.15 & $4.02^{* * *}$ & -1.50 & 1.15 & $4.30^{* * *}$ & -1.43 & 1.09 & $7.85^{* * *}$ & -1.07 \\
\hline 6 & 1.21 & $3.26^{* * *}$ & $-1.91^{*}$ & 1.23 & $3.31^{* * *}$ & $-1.91^{*}$ & 1.08 & $7.62^{* * *}$ & -1.29 \\
\hline 7 & 1.13 & $2.67^{* * *}$ & $-2.34^{* *}$ & 1.14 & $2.73^{* * *}$ & $-2.29^{* *}$ & 1.09 & $7.78^{* * *}$ & -1.55 \\
\hline 8 & 1.12 & $2.85^{* * *}$ & $-2.03^{* *}$ & 1.18 & $3.54^{* * *}$ & $-2.10^{* *}$ & 1.07 & $7.14^{* * * *}$ & -1.55 \\
\hline 9 & 1.13 & $2.74^{* * *}$ & $-2.10^{* *}$ & 1.09 & $2.63^{* * *}$ & $-2.10^{* *}$ & 1.07 & $6.37^{* * *}$ & -1.54 \\
\hline 10 & 1.12 & $3.62^{* * *}$ & $-1.89^{*}$ & 1.17 & $3.64^{* * *}$ & $-1.81^{*}$ & 1.07 & $5.41^{* * *}$ & -1.62 \\
\hline
\end{tabular}




\begin{tabular}{|c|c|c|c|c|c|c|c|c|c|}
\hline \multicolumn{10}{|c|}{ Panel B Multi-day window } \\
\hline & Mean & $\begin{array}{l}\text { t- } \\
\text { statistic }\end{array}$ & Corrado & Mean & $\begin{array}{l}\mathrm{t}- \\
\text { statistic }\end{array}$ & Corrado & Mean & t-statistic & Corrado \\
\hline-1 to 1 & 1.41 & $4.79^{* * *}$ & 1.41 & 1.49 & $4.02^{* * *}$ & 1.39 & 1.27 & $10.11^{* * *}$ & 1.20 \\
\hline-1 to 0 & 1.46 & $5.48^{* * * *}$ & 1.34 & 1.54 & $4.43^{* * *}$ & 1.32 & 1.30 & $12.34^{* * *}$ & 1.18 \\
\hline-1 to 2 & 1.41 & $3.55^{* * *}$ & 0.89 & 1.48 & $3.04^{* * *}$ & 0.86 & 1.24 & $8.15^{* * *}$ & 0.8 \\
\hline \multicolumn{10}{|c|}{ Panel B Multi-day window } \\
\hline $\begin{array}{l}-40 \text { to } \\
40\end{array}$ & 1.46 & $5.87^{* * *}$ & $-6.63^{* * *}$ & 1.35 & & $-7.33^{* * *}$ & 1.31 & $12.18^{* * *}$ & $-11.13^{* * *}$ \\
\hline-40 to 0 & 1.46 & $5.84^{* * *}$ & $-8.04^{* * *}$ & 1.38 & & $-5.82^{* * *}$ & 1.30 & $13.98^{* * *}$ & -0.55 \\
\hline $\begin{array}{l}1 \text { to } \\
40\end{array}$ & 1.46 & $5.79^{* * *}$ & $-7.94^{* * *}$ & 1.31 & & $-6.24^{* * *}$ & 1.32 & $10.35^{* * *}$ & $-4.77^{* * *}$ \\
\hline
\end{tabular}

Notes: The table presents volume reaction around AGMs. Abnormal volume was calculated for volume of shares (shares), value of trades (value) and number of trades (trades). The t-statistic reports the test of the null hypothesis that abnormal volume is zero. Corrado is the Corrado (1989) non-parametric statistic.

Panel B shows the results of the estimation of the multi-day event windows where the estimation window is between -10 and -70 and 11 and 70 days relative to the event day. Panel $\mathrm{C}$ shows the results for the estimation of the multi-day event windows where the estimation window is defined as period between 140 and -40 days relative to the event day. The reported multi-day abnormal volume is the mean for the event window days. The multi-day Corrado statistic is the mean statistic over the multi-day event window multiplied by the square root of the length of the event window. 
Table 5.

Regression results: Time trend in Cumulative Abnormal Return (Cumulative Abnormal Volume)

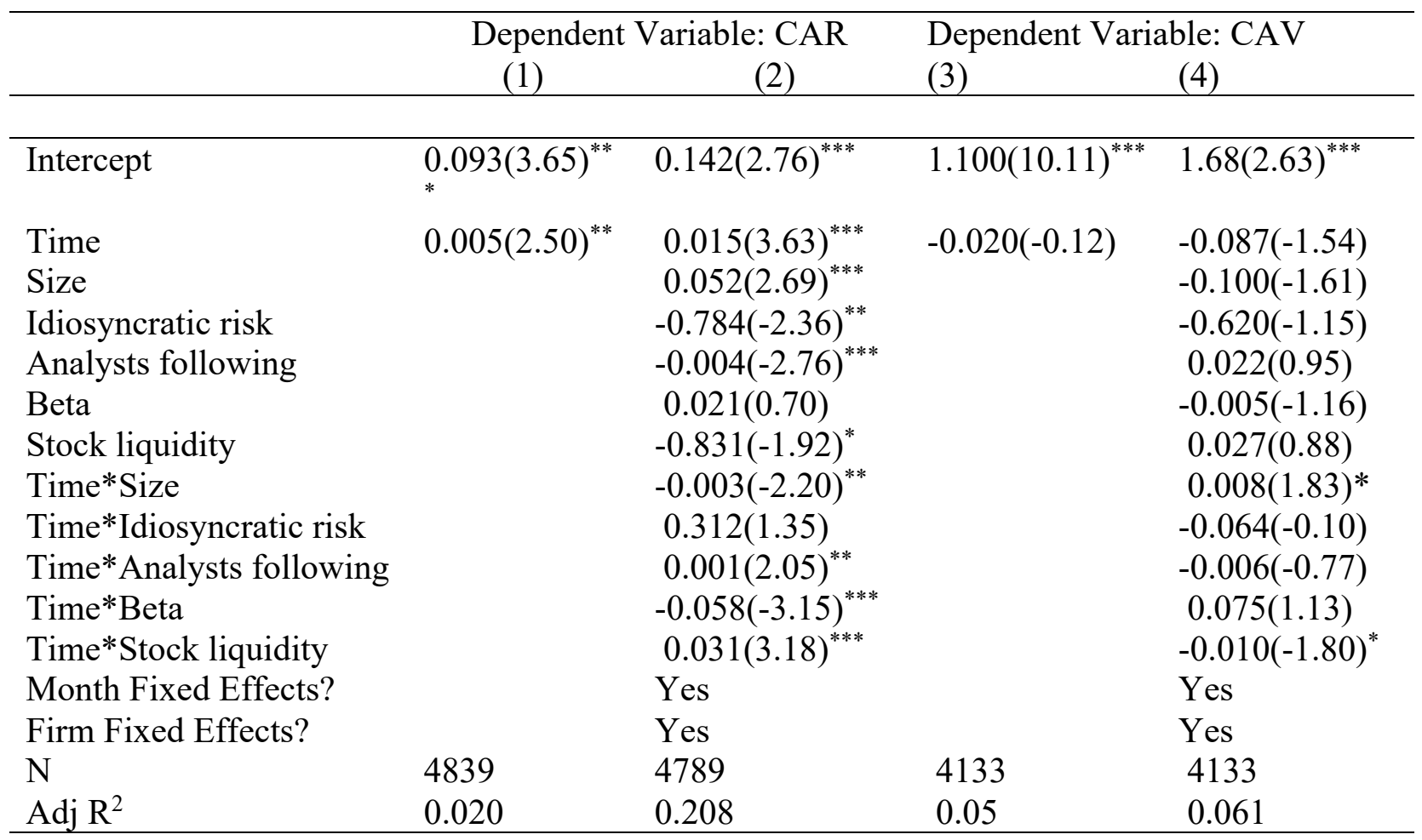

The table presents the regressions of absolute values of cumulative abnormal return (CAR) and cumulative abnormal volume (CAV) against time trend for a sample of AGM dates for the period 2004-2014. Time is a trend variable that takes the value from 1 to 11 across 11 years. Size is the natural logarithm of market capitalisation; idiosyncratic risk is the residual variance from the regression of stock returns on market returns over a period of 48 months preceding the month of the AGM; Beta is the beta value from the regression used in estimating idiosyncratic risk; Analysts following is the number of analysts providing one year ahead earnings estimate for the firm; Stock liquidity is the ratio of average value of stock traded to the average value of shares outstanding over the period of one year preceding the year of the AGM. ${ }^{* * *}$, ${ }^{* *}$ and * indicate significant at $1 \%, 5 \%$ and $10 \%$ levels, respectively. The reported standard errors are heteroscedasticity-robust standard errors clustered at firm level. We winsorise the dependent variable at the $1 \%$ and $99 \%$ levels. 


\section{FIGURE 1}

Pattern of Abnormal Return around Annual General Meetings

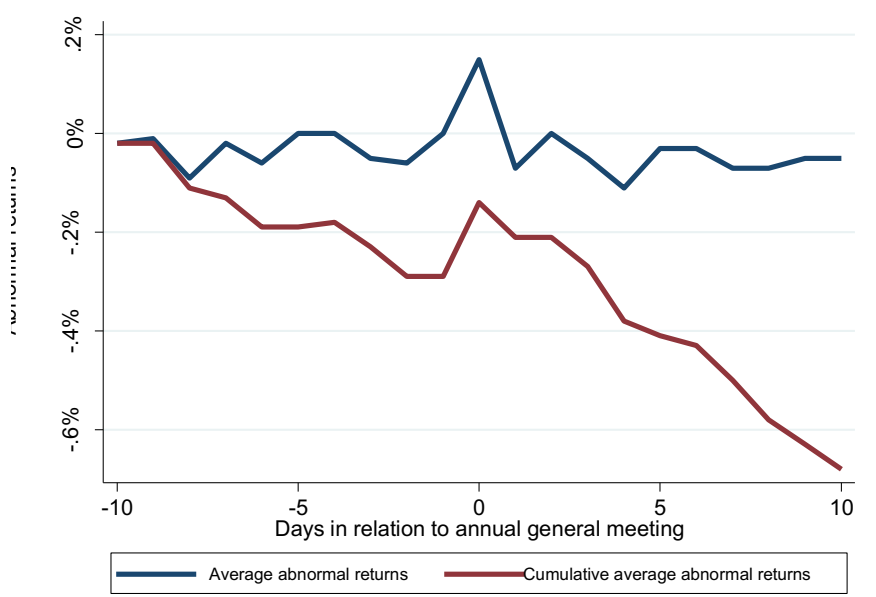


FIGURE 2

Pattern of Abnormal Return around Annual General Meetings

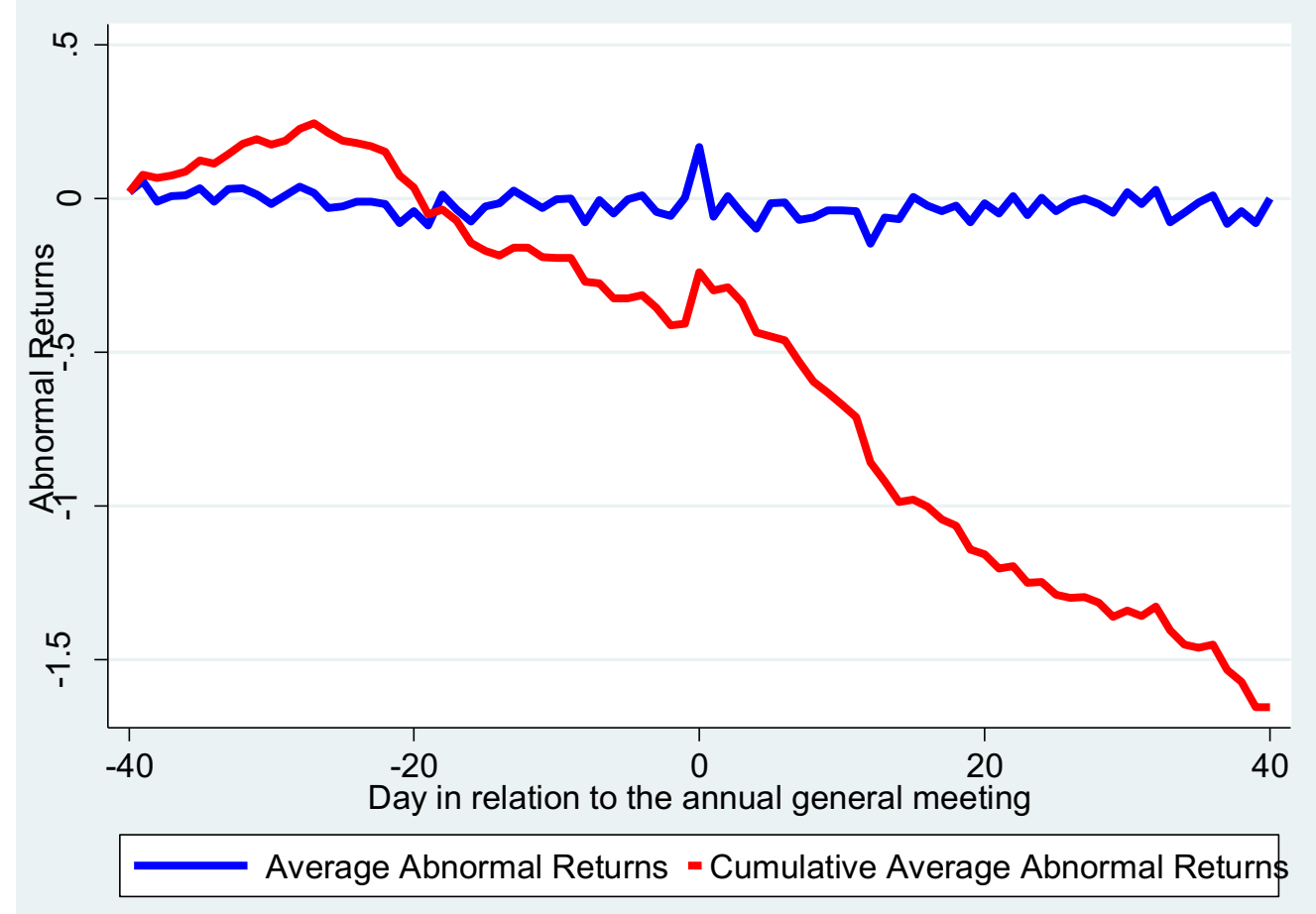


Figure 3

\section{Pattern of Abnormal Volume around Annual General Meetings}
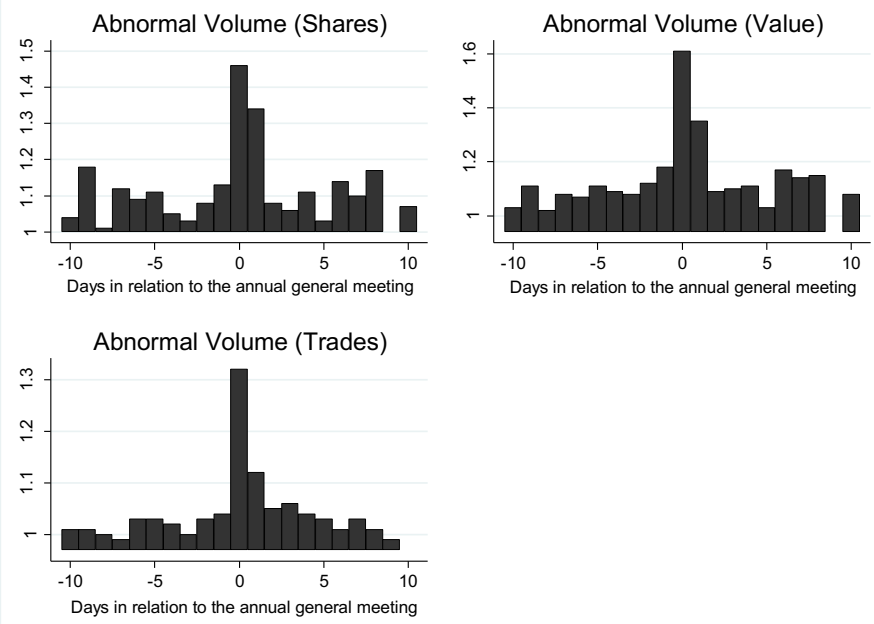

Figure 2: Pattern of abnormal volume around annual general meetings 